\title{
MEDIA PEMBELAJARAN BAHASA INGGRIS INTERAKTIF PICTIONARY
}

\author{
Muhammad Iqbal Ardiansyah Ukkas \\ Desain Komunikasi Visual Fakultas Seni dan Desain Universitas Negeri Makassar \\ email: iqbalad14@gmail.com \\ Dian Cahyadi \\ Desain Komunikasi Visual Fakultas Seni dan Desain Universitas Negeri Makassar \\ email:dian.cahyadi@unm.ac.id \\ Nurabdiansyah \\ Desain Komunikasi Visual Fakultas Seni dan Desain Universitas Negeri Makassar \\ email: nurabdiansyah@unm.ac.id
}

\begin{abstract}
This research was conducted to produce a design of Pictionary English Interactive Learning Media for Kindergarten. The concept of interactive learning media is to introduce children to English vocabulary as early as possible. The material is compiled based on data obtained from books and internet facilities (literature study), the results of interviews directly from Biringkanaya Islamic Kindergarten Jl. Bukit Bontoloe Raya, Observation on location and Documentation, the design of this learning media is expected to be able to (1) be able to help children in kindergarten to recognize English as early as possible (2) improve children's ability to memorize English vocabulary (3) Creating learning media that can make it easier for teachers to teach children English
\end{abstract}

Keywords: learning media, children, english.

\begin{abstract}
Abstrak
Penelitian ini dilakukan untuk menghasilkan sebuah rancangan Media Pembelajaran Interaktif Bahasa Inggris Pictionary untuk Taman kanak-kanak.Konsep media pembelajaran interaktif ini ialah memperkenalkan anak-anak kosa kata Bahasa Inggris sedini mungkin.Materi disusun berdasarkan data yang diperoleh dari buku dan fasilitas internet (Studi pustaka), hasil wawancara langsung dari Taman Kanak-kanak Islam Biringkanaya Jl. Bukit Bontoloe Raya; Observasi pada lokasi serta Dokumentasi, perancangan media pembelajaran ini diharapkan mampu (1) dapat membantu anak di Taman Kanak-Kanak untuk mengenali Bahasa Inggris sedini mungkin (2) meningkatkan kemampuan anak-anak dalam mengingat kosa kata Bahasa Inggris (3) Menciptakan media pembelajaran yang bisa memudahkan guru dalam mengajarkan anak-anak Bahasa Inggris.
\end{abstract}

Kata kunci: media pembelajaran, anak-anak, bahasa inggris. 


\section{PENDAHULUAN}

Bahasa Inggris sendiri harus diajarkan pada anak sejak usia dini karena melihat dampak globalisasi saat ini, Pembelajaran Bahasa Inggris pada anak usia dini dilakukan dengan berbagai macam cara dan secara bertahap diajarkan hanya sebatas pengetahuan atau dasar-dasarnya saja tidak secara mendalam dan proses pembelajaran untuk peserta didik secara aktif mengembangkan potensi dirinya untuk memiliki kekuatan spiritual keagamaan, pengendalian diri, kepribadian, kecerdasan, akhlak mulia, serta keterampilan yang diperlukan dirinya dan masyarakat. Pendidikan dapat diartikan sebagai usaha sadar dan sistematis untuk mencapai taraf hidup atau untuk kemajuan lebih baik. Pembelajaran Bahasa Inggris bisa dilakukan dengan berbagai cara mengikuti perkembangan teknologi itu sendiri. Anak-anak di Indonesia khususnya di Makassar sendiri masih jarang dan tidak sedikit diantara mereka yang masih kesulitan dalam mempelajari Bahasa Inggris, kebingungan ingin memulainya dari mana termasuk dalam penyebutan kata Bahasa Inggris itu sendiri.

\section{Pendidikan Bahasa Inggris perlu diperkenalkan pada anak-anak sejak dini.Namun, pada umumnya anak-anak mengalami kesulitan dalam mempelajari Bahasa asing, termasuk Bahasa Inggris ini.kesulitan anak dalam mempelajari Bahasa Inggris disebabkan karena Bahasa Inggris bukan merupakan bahasa mereka, sehingga mereka tidak terbiasa mendengar atau mengucapkan pelafalan dalam Bahasa Inggris. Selain itu kecenderungan pola belajar anak yang lebih suka bermain juga sangat mempengaruhi, sehingga pembelajaran secara teoritis saja kurang optimal untuk pembelajaran Bahasa Inggris pada anak. Melihat perkembangan teknologi yang semakin pesat, anak-anak akan dengan mudah belajar melalui aplikasi interaktif ataupun media-media terkait.}

Kebanyakan anak-anak usia dini sendiri khususnya di Indonesia bagian Makassar masih sedikit dari mereka yang memiliki niat serius dalam mempelajari Bahasa Inggris, anak-anak sekarang saat ini lebih tertarik mempelajari sesuatu dekat berkaitannya dengan hal-hal yang berbau media visual dengan aktivitas maupun gerakan-gerakan.Peran orang tua terhadap anaknya juga berperan penting dalam proses pembelajaran dengan menggunakan Bahasa Inggris di rumah meskipun dalam waktu yang singkat agar Bahasa Inggris anak semakin berkembang.

Banyaknya aspek-aspek media pembelajaran pada anak-anak usia dini yang tidak kalah pentingnya yaitu, pengenalan kosa kata dalam Bahasa Inggris di sekeliling mereka yang sering mereka jumpai bagi anak umur 5 tahun keatas karena salah satu keterampilan paling penting yang ingin dicapai pada anak usia dini. Karena anak akan lebih cenderung tertarik belajar sambil bermain.

Media sangat diperlukan, guna memperlancar proses komunikasi pembelajaran bagi anak-anak. Melalui media pembelajaran tersebut akan dapat lebih terarah sesuai tujuan yang dikehendaki. Namun diantara tujuan media dalam kegiatan pembelajaran ialah untuk membantu anak lebih cepat mengetahui, memahami, dan upaya terampil dalam mempelajari sebuah materi yang dipelajari, oleh karena itu dibutuhkan media yang sifatnya lebih efektif dan efesien. Selain itu, juga untuk menciptakan suasana pembelajaran yang lebih menarik, dan aktif dengan adanya media pembelajaran yang baru, tujuan pembelajaran akan dapat tercapai lebih mudah.

Media interaktif mengenai aplikasi seputar Bahasa inggris yang dapat dipelajari anak-anak dengan mudah yang berisi kosa-kata Bahasa inggris yang umum dijumpai kehidupan sehari-hari dan dilengkapi dengan gambargambar menarik. Media interaktif diharapkan dapat mampu membantu anak dalam sistem Belajar sambil Bermain yang sangat efektif untuk proses pembelajaran bagi anak-anak dan besar harapan agar dapat sangat bermanfaat untuk masa depan si anak, untuk melanjutkan ke jenjang pendidikan yang seterusnya.

Dengan adanya media pembelajaran ini akan lebih menarik minat belajarnya anak, interaktif, dan menyenangkan sehingga secara tidak langsung kualitas pembelajaran pun dapat ditingkatkan ke arah yang lebih baik. Selain itu, pembelajaran dapat dilakukan kapan dan di mana saja sesuai yang diinginkan. Dengan kata lain, dengan adanya media pembelajaran maka proses belajar akan bisa lebih maksimal. 
Adapun tujuan yang hendak dicapai dalam perancangan ini yaitu :

a. Merancang media interaktif kosa kata Bahasa Inggris sederhana bagi anak usia dini khususnya anak-anak di Taman Kanak Kanak Islam Biringkanaya Jl. Bukit Bontoloe Raya.

b. Membantu meningkatkan kemampuan anak usia dini dalam Berbahasa Inggris.

\section{METODE PENELITIAN}

Perancangan Media interaktif kosakata

Bahasa Inggris pictionary pada pmenggunakan metode kualitatif, metode kualitatif digunakan karena dengan metode tersebut penulis mampu lebih mengetahui informasi atau data-data yang lebih lengkap dan dianalisis menggunakan teknik analisis SWOT sebagai acuan dalam rangka perancangan analisis obyek.

Analisis SWOT dilakukan pada perancangan media yang akan digunakan sebagai acuan untuk membandingkan media utama dan media pendukung yang digunakan, adapun media yang akan dianalisis yaitu buku, maupun software interaktif, sedangkan media pendukung yang digunakan yaitu poster, banner dan motion graphic.

menentukan yaitu usia dan pendidikan, lalu secara psikografis yang menentukan kepribadian dan secara geografis perancangan ini ditunjukkan kepada target audience yaitu anak usia dini Taman Kanak-kanak Islam Biringkanaya Jl. Bukit Bontoloe Raya.

Observasi perancangan yang dilakukan adalah dengan mengunjungi Taman Kanak Kanak Islam Biringkanaya di Jalan BukitBontoloe Raya untuk mengetahui metode pembelajaran yang diajarkan anak-anak usia dini dalam mempelajari Bahasa Inggris melalui teknologi informasi di Taman kanakkanakIslam Biringkanaya Jalan Bukit Bontoloe Raya dan Melakukan pengamatan terhadap halhal yang dilakukan anak-anak dalam menerima pembelajaran, mengamati setiap proses pembelajaran anak-anak terkait bahan dan halhal yang digunakan.

Metode yang digunakan dalam penelitian ini adalah penelitian kualitatif Adapun berdasarkan sumber data, terbagi menjadi 2 jenis :

1. Data primer yang diperoleh melalui wawancara dengan narasumber dalam hal ini narasumber dalam hal ini guru terkait dalam memberikan pelajaran Bahasa Inggris terhadap anak usia dini.

2. Data sekunder yang bersumber dari penelitian-penelitian sebelumnya yang relevan dengan penelitian yang dilakukan dalam bentuk jurnal dan artikel. Data juga didapatkan melalui yang sudah ada yang dapat membantu dalam menganalisis metode pembelajaran anak usia dini dalam pembelajaran Bahasa Inggis melalui media interaktif teknologi informasi.

\section{Metode Pengumpulan Data}

Untuk memperoleh data dan mengetahui keadaan sesungguhnya tentang objek yang menjadi sasaran penelitiandan ketetapan data yang diperlukan, maka metode pengumpulan data yang digunakan yaitu :

\section{1) Wawancara}

Dalam pengumpulan data, penulis melakukan wawancara kepada $\mathrm{Hj}$. Hajrah, S.Sos selaku Kepala Sekolah di Taman Kanakkanak Islam Biringkanaya, Jl. Bukit Bontoloe Raya, tentang penggunaan media-media pembelajaran yang digunakan dalam proses belajar.

Adapun kutipan dalam wawancara yang dilakukan kepada $\mathrm{Hj}$. Hajrah, S.Sos Penulis memberikan pertanyaan tentang media yang diajarkan kepada anak didik, menurut ibu Hajrah banyaknya media yang digunakan tetapi masih sangat sederhana dan hanya sesekali belajar menggunakan laptop sambil menglajar secara online melalui video youtube dan juga menggunakan poster-poster Bahasa Inggris pengenalan huruf dan angka yang ditempel di dinding dan pembelajaran dalam menjelaskan secara verbal atau lisan. Adapun pertanyaan kedua penulis kepada ibu Hajrah yaitu bagaimana minat anak dalam belajar. Menurut ibu Hajrah, tergantung dari apa media pembelajarannya. Contohnya, seperti media pengenalan bentuk yang memiliki ragam warna, karena sifat setiap anak berbeda-beda, maka dari itu media pembelajaran yang digunakan menggunakan warna-warna yang terang dan mereka juga lebih senang bermain sambil 
belajar. penulis kembali bertanya tentang apakah ada media pembelajaran interaktif yang digunakan, ibu Hajrah menjawab bahwa belum ada media pembelajaran interaktif yang digunakan karena masih menggunakan media yang manual saja sesekali online menggunakan laptop/komputer.

Kesimpulan yang diperoleh dari hasil wawancara yang dilakukan terhadap ibu $\mathrm{Hj}$. Hajrah, S.Sos yaitu, kurangnya media pembelajaran unik dan kreatif yang mampu medukung proses belajar mengajar anak-anak yang efektif dan efesien.

\section{2) Observasi}

Observasi perancangan yang dilakukan adalah dengan mengunjungi Taman Kanak Kanak Islam Biringkanaya untuk mengetahui metode pembelajaran yang diajarkan anak-anak usia dini dalam mempelajari Bahasa Inggris melalui teknologi informasi di taman kanakkanak Jalan Bukit Bontoloe Raya.

\section{3) Dokumentasi}

Dilaksanakan dengan cara pemotretan dengan cara memotret pengajaran yang dilakukan oleh gurunya dalam pengajaran Bahasa Inggrisuntuk memperkuat dan melengkapi data-data yang diperoleh.

\section{HASIL DAN PEMBAHASAN 3.1. Konsep Desain}

Konsep desain utama yang diusung dalam perancangan multimedia interaktif ini ialah "Fresh",yang dimana konsep akan menggunakan warna-warna yang segar dan juga cerah yang sebagaimana kita tahu bahwa anakanak lebih tertarik dengan gambar-gambar yang lebih menarik dengan paduan warna yang sesuai untuk anak-anak.

Pelajaran Bahasa Inggris sendiri bisa ditanamkan sejak usia dini karena usia dini merupakan usia golden age, yang dimana anak usia dini lebih mudah menyerap pelajaran dibanding anak yang sudah melewati masa pubertas.

Pada akhirnya konsep desain meliputi warna-warna yang segar dan cerah agar gampang masuk di otak anak-anak nantinya yang dapat diaplikasikan dan dijadikan sebagai main konsep untuk anak usia dini, yang diharapkan dapat terkomunikasikan secaravisual sehingga informasi dapat tersampaikan dengan baik.

Dari hasil analisa objek/materi komunikasi sebelumnya, memilih materi "Belajar yang Asyik" Dimana belajar merupakan acuan utama untuk mengasah kemampuan anak yang akan diberangi dengan bermain. Karena bermain juga perlu agar anak merasa bahwa belajar tidak harus selalu serius. Sehingga proses perancangan ini akanmerancang sebuah

media pembelajaran berupa multimedia interaktif tentang kosa kata Bahasa Inggris yang sering anak-anak jumpai di lingkungan sekitar dengan desain paduan warna yang cerah dan segar dan juga disertai audio untuk memperkenalkan objek seperti anggota tubuh, buah-buahan, hewan, sayuran, angka dan juga warna.

Dengan cara menekan gambar dari kosa kata materi sendiri maka akan muncul suara dari pengucapan pengejaan dalam Bahasa Inggris dan juga diberikan ejaan dalam Bahasa Inggris dan Bahasa Indonesia untuk membantu anak agar mudah mengingat setiap kosa katanya. Sedangkan konsep bermain diberikan sebuah kuis tebak gambar atau suara baik dalam Bahasa Inggris dan Bahasa Indonesia secara acak.Agar anak mudah mengingat kembali tentang kosa kata Bahasa Inggris yang sudah dijelaskan sebelumnya. Pada perancangan ini yang menciptakan cara belajar yang menyenangkan disesuaikan dengan hasil analisis data.

Pemilihan konsep komunikasi sesuai dengan konsep desain. Penyampaian materi yang akan disampaikan kepada anak-anak mudah dicerna agar dapat belajar dengan menyenangkan.

\subsection{Materi Perancangan}

Materi yang dijadikan objek media utama pada perancangan media pembelajaran pengenalan kosa kata Bahasa Inggris ini dalam bentuk multimedia interaktif bergaya kartun dengan teknik pengerjaan digital painting. Disertai kuis-kuis atau evaluasi sederhana tentang Angka, hewan, buah-buahan, anggota tubuh, sayuran dan warna secara acak dalam Bahasa Inggris dan Bahasa Indonesia agar anak mudah mengingat kembali materi yang sudah 
dipelajari sebelumnya. Konten materi kemudian dibagi ke dalam enam sesi, seperti dibawah ini :

\section{Body atau Anggota Tubuh}

Berdasarkan analisis materi adapun anggota tubuh atau 'body' yang diangkat dalam materi Pictionary, yaitu; Arm, Cheek, Chest, Ear, Eye, Eyebrow, Finger, Foot, Forehead, Hair, Hand, Knee, Leg, Mouth, Neck, Nose, Stomach.

\section{Animals atau Hewan}

Pengenalan hewan dalam Bahasa Inggris yang akan diangkat, yaitu; Bear, Cat, Chicken, Cow, Dog, Donkey, Duck, Elephant, Frog, Goat, Horse, Lion, Sheep, Tiger, Wolf.

\section{Vegetables atau Sayuran}

Pengenalan sayuran dalam Bahasa Inggris yang diperkenalkan, yaitu; Broccoli, Cabbage, Carrot, Chilli, Corn, Eggplant, Garlic, Mushroom, Onion, Red Onion, Paprika Potato, Pumpkin, Radish, Tomato.

\section{Fruits atau Buah-buahan}

Pengenalan buah-buahan dalam Bahasa Inggris yang diangkat, yaitu; Apple, Banana, Grape, Lemon, Orange, Papaya, Rambutan, Strawberry, Watermelon, Manggo, Cherry, Pear, Dragon Fruit.

\section{Numbers atau Angka-Angka}

Pengenalan Angka-angka dalam Bahasa Inggris yang diangkat, yaitu; One, Two, Three, Four, Five, Six, Seven, Eight, Nine, Ten.

\section{Colors atau Warna}

Pengenalan Warna dalam Bahasa Inggris yang diangkat, yaitu; Black, Blue, Brown, Gray, Green, Orange, Pink, Purple, Red, White, Yellow, Light Blue.

\subsection{Media Utama}

Media utama dalam perancangan ini adalah media aplikasi flash interaktif yang dapat ditampilkan menggunakan Laptop,Media aplikasi flash interaktif ini memiliki format .exe dengan resolusi 1928 x 1080 px dengan kapasitas $138 \mathrm{MB}$ yang tersimpan dalam media pendukung berupa USB Card.

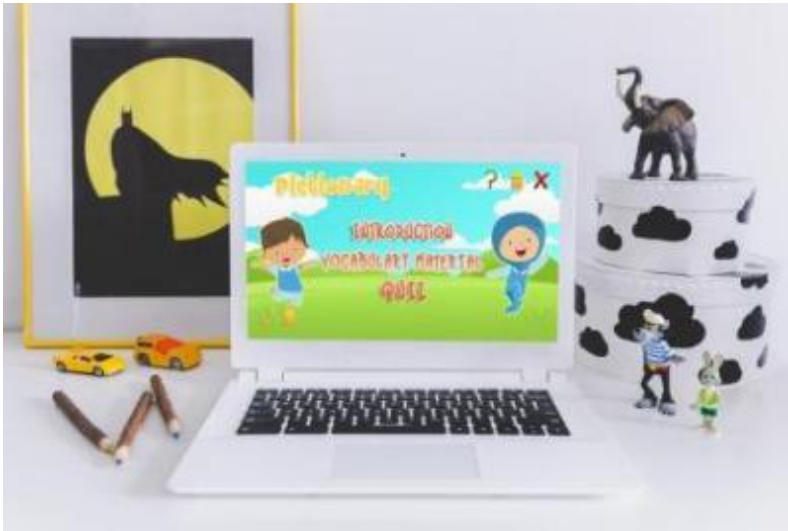

Gambar 3.1. Tampilan ilustrasi media aplikasi flash interaktif dalam Laptop.

Media interaktif ini menyajikan informasi mengenai pembelajaran kosa kata Bahasa Inggris dengan tampilan grafis halaman muka menghadirkan dua orang anak usia kanakkanak, laki-laki pada sebelah kiri dan kanakkanak peempuan pada sebelah kanan berlatar di suatu hamparan padang nan hijau dengan barisan perbukitan dan gunung di belakangnya. Dihadirkan dengan warna-warna segar alam pegunungan.

Media ini terdiri dari 3 tombol yang menyajikanmateri informasi di dalamnya terdapat tiga bagian yaitu Introduction, Vocabulary Material, danQuiz.

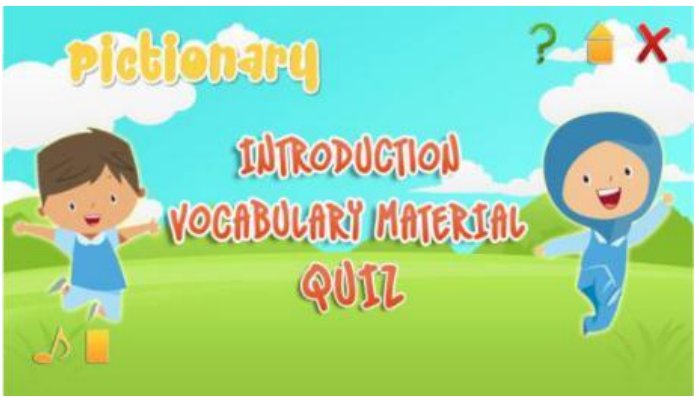

Gambar 3.2 Menu utama media interaktif

1. Tombol Introduction memberikan informasi mengenai pembahasan soal pentingnya pembelajaran Bahasa Inggris sebagai pengantar pembahasan untuk materi kosa kata. 


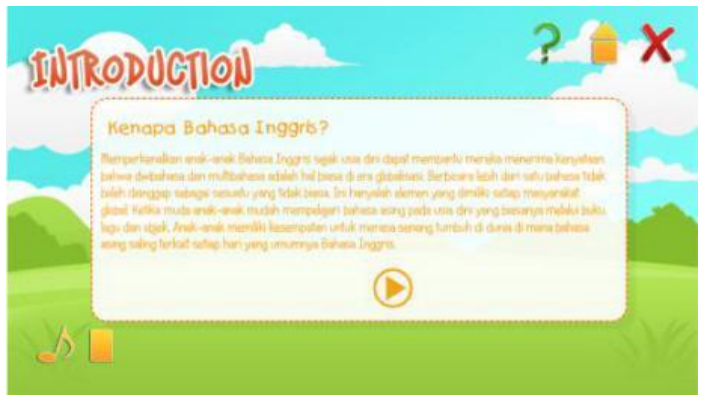

Gambar 3.3. Tombol Introduction

2. Tombol Vocabulary Material merupakan pembahasan dari kosa kata Bahasa Inggris ini, Pada Tombol Vocabulary Material, audience akan diberikan informasi 6 kosa kata Bahasa Inggris yaitu Body, Animals, Fruits, Vegetables, Colors dan Numbers

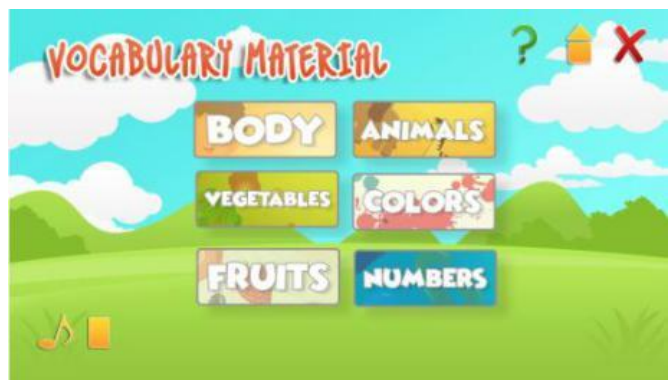

Gambar 3.4. Tombol vocabulary material

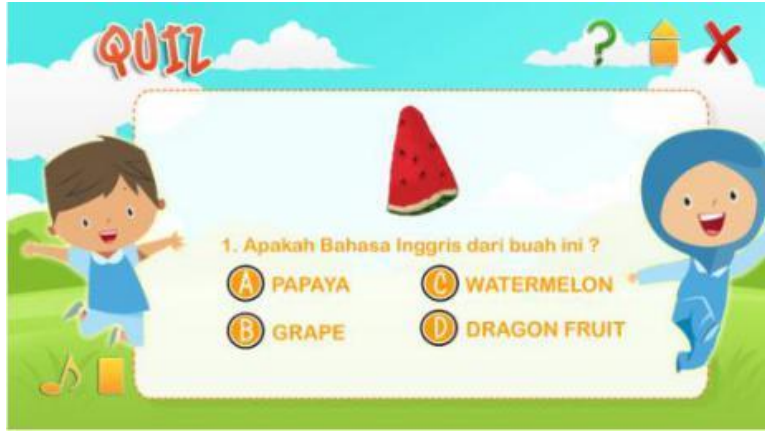

Gambar 3.5 Tombol Quiz

3. Pada tombol ketiga, Audience akan di ajak untuk ikut bermain Quiz seputar kosa kata Bahasa Inggris yang ada pada tombol ketiga.

\section{KESIMPULAN}

Dari hasil perancangan media pembelajaran bahasa inggris pictionary untuk anak usia dini, maka diperoleh kesimpulan sebagai berikut :

1. Media Pembelajaran Interaktif dirancang berdasarkan permasalahan yang terjadi di
Taman Kanak-kanak Islam Biringkanaya di Jl. Bukit Bontoloe Raya Makassar mengenai pembelajaran kosa-kata Bahasa Inggris untuk anak usia dini dengan menggunakan materi umum yang akan dijadikan objek media utama pada perancangan, pengenalan kosa kata Bahasa Inggris ini dalam bentuk multimedia interaktif dengan gaya kartun beserta kuis.

2. Dihasilkan Media Interaktif kosa kata Bahasa Inggris dalam perancangan ini adalah media aplikasi flash interaktif yang dapat ditampilkan menggunakan laptop, media aplikasi flash interaktif ini memiliki format .exe dengan resolusi 1928 x 1080 px dengan kapasitas 138 MB yang tersimpan dalam media pendukung berupa USB Card tentang pengenalan kosa kata Bahasa Inggris yang sering dijumpai anak-anak dilingkungan sekitar.Sesuai dengan konsep anak-anak akan mengenal angka, hewan, buahbuahan, anggota tubuh, sayuran dan warna dan menggunakan audio berupa dubber suara beserta gambar.

\section{REFERENSI}

Aisyah, Siti. 2011. Perkembangan dan Konsep Dasar Pengembangan Anak Usia Dini. Jakarta: Universitas Terbuka.

Arby, Suharyanto. 2013. Pengaruh warna pada psikologi anak dari Dosen psikologi:https://dosenpsikologi.com/ pengaruh-warna-pada psikologi-anak

Andry, Koniho dan Kusrini 2007. Tuntunan Praktis Membangun Sistem Informasi. Jakarta: ELIB UNIKOM.

Arifin, Irfan, Dian Cahyadi, Abdul Azis Said. 2017. Perancangan Media Pembelajaran. Makassar. Universitas Negeri Makassar.

Arsyad, A. (2002) Media Pembelajaran edisi 1.Jakarta: PT. Raja Grafindo Persada

Asnawir, M. Basyiruddin. 2002 Media Pembelajaran Jakarta: Ciputat Pers.

Hartati, Sri. 2010. Bahan Ajar Perencanaan Pembelajaran TK. UNP.

Helmiah, Fauriatun dan Hardianti, Cici. 2017. Perancangan Media Interaktif Kumpulan Doa Untuk Anak Usia Dini Berbasis Multimedia. Kisaran: Jl. Imam Bonjol No. 179

Irfan, Nurabdiansyah. 2014. Karakteristik Tipografi pada Desain Iklan Komersial Majalah Makassar terkini 
edisi Januari-Desember, Makassar: Universitas Negeri Makassar.

Ladjamudin, Al-Bahra Bin. 2005. Analisis dan Desain Sistem Informasi. Yogyakarta: Graha Ilmu.

Lenneberg, E. H. 1967. Biological Foundation of Language.

Majid, Abdul. 2008. Perencanaan Pembelajaran (Mengembangkan Standar Kompetensi Guru. Bandung: PT Remaja Rosdakarya.

Masitoh, dkk. 2005 Strategi Pembelajaran TK. Yogyakarta: Pustaka Pelajar

Munir. 2012. Multimedia Konsep dan Aplikasi dalam Pendidikan. Bandung: Alfabeta.

Sanjaya, Prof Dr. Wina M,Pd 2012. Klasifikasi Media Jakarta: Kencana prenada media group.

Sujiono, Yuliani Nurani. 2009. Konsep Dasar Pendidikan Anak Usia Dini. Yogyakarta: Laksana

Taggiling, Nur Alfa. 2017. Perancangan media pembelajaran pengenalan nama buah dan hewan dalam bahasa inggris bahasa bugis dan bahasa indonesia bagi anak usia dini. Makassar: Universitas Negeri Makassar.

Uno, Hamzah B. 2008. Perencanaan Pembelajaran. Jakarta: PT. Bumi Aksara.

Widijantie, Nunung. 2012. Pentingnya Pembelajaran bahasa inggris sejak Usia Dini (Jakarta)

Oktafiani, Rini. 2015. Perancangan media interaktif pengenalan alat musik tradisional dan modern anak usia 4-6 tahun. Bandung: Desain Komunikasi Visual Universitas Bina Sarana Informatika. Jln. Cisitu lama no. 12/160d dago.

Mashar, Riana. 2011. Emosi Anak Usia Dini dan Strategi

Pengembangannya Jakarta: Kencana Prenada Media Group.

Nainggolan, Sri Yanti. 2018. Pentingnya memiliki kemampuan berbahasa di usia dini dari Metrotvnews: http://rona.metrotvnews.com/keluarga /ob3V0Z0N-pentingnya-memiliki kemampuan-berbahasa-di-usia-dini/

Dessyanti, 2009. Prinsip-prinsip pembelajaran anak dari Metrotvnews: http://edukasi.kompasiana.com/2009/ 12/29/prinsip-prinsip-pembelajarananak/ 